\title{
Environmental Variance Components of Fruit Ripening Date as Used in Both Phenotypic and Marker-assisted Selection in Japanese Pear Breeding
}

\author{
Sogo Nishio ${ }^{1}$, Masahiko Yamada, Yutaka Sawamura, Norio Takada, \\ and Toshihiro Saito \\ National Institute of Fruit Science, 2-1 Fujimoto, Tsukuba, Ibaraki 305-8605, \\ Japan
}

Additional index words. genetic variance, optimum evaluation, Pyrus pyrifolia, QTL

\begin{abstract}
The effectiveness of detected quantitative trait loci (QTLs) and molecular markers associated with them in tree fruit breeding is measured by the percentages of the variance associated with detected QTL effects accounting for not phenotypic variance, but genetic variance of the trait. The genetic variance can be obtained by subtracting environmental variance from the phenotypic variance. Once accurate environmental variance components are obtained for a given selection field, environmental variances under any number of replications and measurement repetitions can be estimated. We estimated environmental variance components of fruit ripening date measured by days in a Japanese pear (Pyrus pyrifolia Nakai) breeding field in the National Institute of Fruit Tree Science, Tsukuba, Ibaraki, Japan. We estimated variance among fruits within a tree $\left(\sigma_{f}^{2}\right)$ as 25.6, among trees within a genotype $\left(\sigma_{t}^{2}\right)$ as 0.2 , among years $\left(\sigma_{y}^{2}\right)$ as 9.4 , associated with genotype $\times$ year interaction $\left(\sigma_{g y}{ }^{2}\right)$ as 7.9 , and associated with tree $\times$ year interaction $\left(\sigma_{t y}{ }^{2}\right)$ as 1.2. Because $\sigma_{f}^{2}$ was the largest environmental variance component, increasing the number of fruit evaluated would most effectively reduce the environmental variance, and tree replication would not because of very small $\sigma_{t}{ }^{2}$ and $\sigma_{t y}{ }^{2}$. The $95 \%$ confidence limit of a genotypic value was $\pm \mathbf{1 0}$ days in the evaluation of five fruits on a single tree in a year and \pm 7 days over 2 years. Broad-sense heritability in a family, each offspring in which was evaluated using five fruits on a single tree in a single year, was estimated at $\mathbf{0 . 8 3}$ for three full-sib families analyzed.
\end{abstract}

In plant breeding, many seedlings must be tested to increase the chance of obtaining desirable genotypes. The number of seedlings used in tree fruit breeding is more restricted than in annual crop breeding because fruit trees are large and slow-growing. The success rate and cost are almost directly related to the space the trees occupy and for how long (Hansche, 1983).

The establishment of molecular markers of a fruit trait to identify the genotype of offspring for a fruit trait at the seedling stage without having to wait 3 to 5 years for the plant to fruit offers a tremendous advantage and saving in time, space, and money. Even for characters evaluated using vegetative organs such as disease resistance, the phenotypic performance can fluctuate depending on the development stage of shoots evaluated and on environmental conditions such as temperature and humidity. Selection using molecular markers that identify a genotype can be done accurately with low cost and time

Received for publication 5 July 2011. Accepted for publication 6 Sept. 2011.

This research owes a debt to the many persons involved in Japanese pear breeding at NIFTS. We are sincerely grateful for their efforts.

${ }^{1}$ To whom reprint requests should be addressed; e-mail nishios@affrc.go.jp. expenditure, regardless of plant and environmental conditions.

Some molecular markers associated with QTLs of fruit have been developed in some fruit crops in genomic studies (Graham et al., 2009; Kenis et al., 2008; Moriya et al., 2010; Quilot et al., 2004; Segura et al., 2009; Zhang et al., 2010). Because important target traits such as fruit ripening time, fruit weight, and sugar content are quantitative, the fluctuation of phenotypic values with environmental conditions hinders the identification of useful molecular markers. The efficiency of detecting molecular markers associated with a target trait depends on broad-sense heritability in QTL analysis in addition to the genetic marker density on linkage maps (Ukai, 2000).

Japanese pear (Pyrus pyrifolia) is an important fruit crop in Japan, ranking third in production after citrus and apple (Kanayama, 2006). 'Kosui' and 'Hosui', released by the National Institute of Fruit Tree Science (NIFTS), are the current leading cultivars in Japan and occupy $65 \%$ of the total area of Japanese pear orchards in Japan (Tamura, 2006). The Japanese pear breeding program, begun in 1909 (Kajiura and Sato, 1990), continues to aim at developing new cultivars that ripen at various times with high productivity and fruit quality, low production costs, high disease resistance, and freedom from physiological disorders. One of the most important targets of the NIFTS Japanese pear breeding program is to develop superior early-ripening cultivars, which are currently lacking; most fruits are harvested after July in Japan.

Some useful DNA markers have been developed for Japanese pear breeding. $S_{4}{ }^{s m}$ haplotype-specific DNA markers to identify self-compatibility (Okada et al., 2008), a molecular marker associated with the pear scab resistance gene Vnk (Terakami et al., 2006), and one associated with black spot disease (Terakami et al., 2007) facilitate breeding because genotypes for these traits are controlled by a single gene at a single locus.

NIFTS has constructed a genetic linkage map of Japanese pear from simple sequence repeat and amplified-fragment-length polymorphism markers (Iketani et al., 2001; Nishitani et al., 2009; Terakami et al., 2009; Yamamoto et al., 2007).

So far, the effectiveness of detected QTLs and molecular markers associated with them has been often assessed by the percentages of the variance of the detected QTL effects accounting for the observed phenotypic population variance of the trait (Graham et al., 2009; Kenis et al., 2008; Moriya et al., 2010; Quilot et al., 2004; Segura et al., 2009; Zhang et al., 2010). However, phenotypic variance contains both genetic and environmental variance components. The effectiveness of detected QTLs essentially depends on the percentage of the variance of the detected QTL effects accounting for the genetic variance of the trait. When molecular markers associated with the detected QTLs explain most of the genetic variance, the selection based on the molecular markers is very effective even if the percentage of the variance of the detected QTL effects accounting for the phenotypic variance is low. Therefore, it is needed to estimate the genetic variance for assessing the detected QTL effects. However, reports on molecular markers associated with QTLs in tree fruit breeding do not show the genetic variance (Graham et al., 2009; Kenis et al., 2008; Moriya et al., 2010; Quilot et al., 2004; Segura et al., 2009; Zhang et al., 2010).

Genetic variance in tree fruit crops that are propagated vegetatively can be easily estimated by subtracting environmental variance from phenotypic variance. Environmental variance in a given field (orchard) comprises variance among years, among trees within a genotype, among fruit within a tree, the genotype $\times$ year interaction variance, and the tree $\times$ year interaction variance, all of which can be estimated from repeated measurements of replications of several genotypes (Hansche and Beres, 1966; Hansche and Brooks, 1965; Sato et al., 2000; Yamada et al., 1993, 2002). Once accurate environmental variance components are obtained in the field, environmental variances under any numbers of replications and measurement repetitions can be estimated (Nyquist, 1991; Yamada et al., 1993, 2002).

Abe et al. (1993) reported a small environmental variance in fruit ripening date (FRD) of Japanese pear seedlings, but their experiment covered only 2 years, and they 
did not estimate the environmental variance components of the tree $\times$ year interaction or the tree and fruit effects.

The objective of our study was to obtain accurate estimates of the environmental variance components of FRD, which is usually used for practical phenotypic selection, as used in further studies assessing detecting QTLs, based on a large data set including several yearly repetitions. Environmental variance components have been obtained by analysis of variance (ANOVA) in many fruit crops (Hansche and Beres, 1966; Hansche and Brooks, 1965; Sato et al., 2000; Yamada et al., 1993, 2002). We did the same here.

QTL analysis is often made using an offspring population from a cross (Graham et al., 2009; Kenis et al., 2008; Moriya et al., 2010; Quilot et al., 2004; Segura et al., 2009; Zhang et al., 2010). Genetic variance can be estimated from estimates of environmental variance components in such a population. Therefore, we additionally estimated the genetic variance and heritability of FRD in a family (cross) using some $F_{1}$ full-sib families.

\section{Materials and Methods}

Expts. 1 and 2 used Japanese pear cultivar/ selection trees grown at NIFTS, Tsukuba, Japan. These trees were often used as the standards in evaluating the performance in offspring of Japanese pear cross-breeding, which fluctuates yearly. The trees ranged from 4 to 22 years old in 1993 and were maintained with cultural techniques used in commercial production in Japan (Tamura, 2006): trained on horizontal trellises, pruned in winter, and treated for pests and diseases. Fruits were thinned to one per three fruit clusters in mid-May and harvested at their respective FRD during late July to October according to a color chart that indicates the optimum ground color for picking Japanese pear (Kajiura et al., 1975). The optimum ground color for picking was determined by the time that fruit skin color in the calyx end changes from green to the color corresponding to plate 4 of the ground color chart. FRD was expressed as number of the days since 1 Jan.

Standard deviations (SDS) of the FRD for genotypes in each year for 20 randomly selected fruits from a single tree in each of 21 cultivars/selections for 7 years during 1993 to 2005 ranged stably from 17 to $20 \mathrm{~d}$. Using the data, SDS of FRDs for years in each cultivar/ selection ranged from 2.6 to $8.7 \mathrm{~d}$. Bartlett's test for both variances for genotypes in each year and variances for cultivars/selections in each year did not decline the homogeneity at $P$ $=0.05$. Those results suggested that the environmental variance in the NIFTS field did not change significantly with year or genotype.

\section{Expt. 1: Estimation of variance among fruits within a tree $(20$ fruits $\times$ two trees $\times$ eight cultivars, 1 year)}

The harvest dates (=FRD) of 20 randomly selected fruits from two trees of each of eight cultivars (Table 1) in 2005 were analyzed by ANOVA with the following random model. Variation among branches within a tree was neglected because cultural practices minimize this. The model for the phenotypic value of FRD $\left(P 1_{i j k}\right)$ for the $k$ th fruit of the $j$ th tree of the $i$ th genotype (cultivar or selection) is expressed as

$$
P 1_{i j k}=\mu 1+g 1_{i}+t 1_{i j}+f_{i j k}
$$

where

$\mu l=$ a constant value (the overall mean), $g 1_{i}=$ the genotypic effect of the $i$ th genotype,

$t 1_{i j}=$ the effect of the $j$ th tree of the $i$ th genotype, and

$f_{i j k}=$ the effect of the $k$ th fruit of the $j$ th tree of the $i$ th genotype.

Bartlett's test using raw data did not reject the homogeneity of variances within a tree at $P=0.05$. ANOVA provided the variance among genotypes $\left(\sigma_{g l}{ }^{2}\right)$, among trees within a genotype $\left(\sigma_{t l}{ }^{2}\right)$, and among fruits within a tree $\left(\sigma_{f 1}^{2}\right)$.

Expt. 2: Estimation of variance among years, among trees, associated with genotype $\times$ year interaction, and associated with tree $\times$ year interaction (two trees $\times$ eight cultivars, 12 years)

The per-tree mean FRD values of 20 fruits from two trees of each of the eight cultivars used in Expt. 1 for 12 years (between 1993 and 2006) were analyzed by ANOVA. The random model for the phenotypic value of $\operatorname{FRD}\left(P 2_{i j k}\right)$ of the $j$ th tree of the $i$ th genotype in the $k$ th year is

$P 2_{i j k}=\mu 2+g 2_{i}+t 2_{i j}+y 2_{k}+(g y 2)_{i k}+r 2_{i j k}$

where

$\mu 2=a$ constant value (the overall mean), $g 2_{i}=$ the genotypic effect of the $i$ th genotype, $t 2_{i j}=$ the effect of the $j$ th tree of the $i$ th genotype,

$y 2_{k}=$ the effect of the $k$ th year,

$(g y 2)_{i k}=$ the interaction between the $i$ th genotype and the $k$ th year, and

$r 2_{i j k}=$ the residual effect in the $j$ th tree of the $i$ th genotype in the $k$ th year.

ANOVA provided the variance among genotype $\left(\sigma_{g 2}{ }^{2}\right)$, among trees within a genotype $\left(\sigma_{t 2}{ }^{2}\right)$, among years $\left(\sigma_{y 2}{ }^{2}\right)$, associated with the genotype $\times$ year interaction $\left(\sigma_{g y 2}{ }^{2}\right)$, and the residual $\left(\sigma_{r 2}{ }^{2}\right.$ : composed of the variance associated with the tree $\times$ year interaction and $1 / 20$ of the variance among fruits). Variance associated with tree $\times$ year interaction $\left(\sigma_{t y 2^{2}}\right)$ was estimated as $\sigma_{\mathrm{r} 2}{ }^{2}$ $\left(\sigma_{\mathrm{fl}}{ }^{2} / 20\right)$. The distribution of the residual estimates was not significant at $P=0.05$ by the one-sample Kolmogorov-Smirnov test (Campbell, 1974), and it approached a normal distribution.

Incorporation of the environmental variance components estimated in Expts. 1 and 2. Choosing the estimates having the largest degrees of freedom (df) in Expts. 1 and 2, we defined the variance among years $\left(\sigma_{y}{ }^{2}\right)$ as $\sigma_{y 2}{ }^{2}$, associated with the genotype $\times$ year interaction $\left(\sigma_{g y}{ }^{2}\right)$ as $\sigma_{g y 2}{ }^{2}$, among trees within a year $\left(\sigma_{t}^{2}\right)$ as $\sigma_{t 2}{ }^{2}$, associated with the tree $\times$ year interaction $\left(\sigma_{t y}{ }^{2}\right)$ as $\sigma_{t y 2}{ }^{2}$, and among fruit within a tree $\left(\sigma_{f}^{2}\right)$ as $\sigma_{f 1}^{2}$.

\section{Expt. 3: Estimation of genetic variance and heritability in a full-sib family from a cross}

The harvest dates (=FRD) in 2009 of five fruits of a total of 177 offspring population from three full-sib families were subjected to ANOVA in one-way classification with the factor of family. The population was composed of 60 offspring from 'Akiakari' $\times$ 'Taihaku', 65 offspring from 'Shinsei' $\times$ 'Akibae', and 52 offspring 'Shinsei' $\times$ 426-59 (a selection derived from 'Hosui', 'Niitaka', and 'Nijisseiki'). The FRD of each offspring was evaluated for five fruits in a single tree in 2009.

The ANOVA model for the phenotypic value of FRD $\left(P 3_{i j}\right)$ of the $j$ th offspring of the $i$ th family (cross) is expressed as

$$
P 3_{i j}=\mu 3+(g f)_{i}+(p o)_{i j}
$$

where

$\mu 3=$ a constant value (the overall mean), $(g f)_{i}=$ the genetic effect of the $i$ th family (cross), and

$(p o)_{i j}=$ the effect of the $j$ th offspring of the $i$ th family (cross).

Bartlett's test using raw data did not reject the homogeneity of variances within family at $P=0.05$, meaning that within-family variance resulting from $(p o)_{i j}$ is homogeneous over families, and the within-family variance estimate obtained by ANOVA can be commonly used for the three families with a high df.

Table 1. The eight Japanese pear cultivars used in Expts. 1 and 2.

\begin{tabular}{llc}
\hline Cultivar & \multicolumn{1}{c}{ Origin } & $\begin{array}{c}\text { Mean fruit ripening date } \\
\text { (day of year) }\end{array}$ \\
\hline Choju & F1 of Asahi $\times$ Kimitsukawase & 12 Aug. \\
Gold Nijisseiki & Bud mutant of Nijisseiki & 26 Sept. \\
Hosui & F1 of Hakko $\times 75-23$ & 16 Sept. \\
Kosui & F1 of Kikusui $\times$ Wasekozo & 28 Aug. \\
Niitaka & F1 of Amanogawa $\times$ Chojuro & 2 Oct. \\
Shinsei & F1 of Suisei $\times$ Shinko & 24 Sept. \\
Shinsui & F1 of Kikusui $\times$ Kimitsukawase & 17 Aug. \\
Yakumo & F1 of Akaho $\times$ Nijisseiki & 22 Aug. \\
\hline
\end{tabular}

75-23 = F1 of Nijisseiki $\times$ Ri-14 (Kikusui $\times$ Yakumo). 
ANOVA provided the genetic variance among families $\left(\sigma_{g f}^{2}\right)$, within-family variance $\left(\sigma_{p o}{ }^{2}\right)$. The $(p o)_{i j}$ was composed of the genetic and environmental effect of the $j$ th offspring of the $i$ th family (cross): $(p o)_{i j}=(g o)_{i j}+e_{i j}$

where

$(g o)_{i j}=$ the genotypic effect of the $j$ th offspring of the $i$ th family (cross), and $e_{i j}=$ the environmental effect of the $j$ th offspring of the $i$ th family (cross).

All the data were obtained in a single year; therefore, no year effects as shown in the Expt. 2 model were assumed. The variance of $e_{i j}\left(\sigma_{e}^{2}\right)$ was composed of one-fifth of variance among fruits within tree $\left(\sigma_{f}^{2}\right)$, variance among trees within genotype $\left(\sigma_{t}^{2}\right)$, and variance associated with genotype $\times$ year interaction $\left(\sigma_{g y}{ }^{2}\right)$, and tree $\times$ year interaction $\left(\sigma_{t y}{ }^{2}\right)$. The genetic variance within a family (cross) $\left(\sigma_{g o}{ }^{2}\right)$ was estimated as $\sigma_{p o}{ }^{2}-\sigma_{e}{ }^{2}$. Broad-sense heritability in a family (cross) was estimated as $\left(\sigma_{g o}{ }^{2} / \sigma_{p o}{ }^{2}\right)$ commonly for the three families.

\section{Results and Discussion}

Expt. 1: Estimation of variance among fruits within a tree $(20$ fruits $\times$ two trees $\times$ eight cultivars, 1 year)

ANOVA showed that the genotypic effect was highly significant, but the tree effect was $\operatorname{not}\left(P=0.05\right.$; Table 2). $\sigma_{g l}{ }^{2}=393.5, \sigma_{t 1}{ }^{2}=$ 1.6, and $\sigma_{f 1}{ }^{2}=25.6 . \sigma_{g l}{ }^{2}$ accounted for $94 \%$ of the total variance $\left(\sigma_{T 1}^{2}\right)$, because the FRD of the cultivars ranged widely from early August to mid-October.

Because the data covered a single year, $\sigma_{g l}{ }^{2}$ was composed of the true genotypic variance over years $\left(\sigma_{g}{ }^{2}\right)$ and the variance associated with genotype $\times$ year interaction $\left(\sigma_{g y}{ }^{2}\right)$ in the Expt. 2 model. Likewise, $\sigma_{t 1}{ }^{2}$ was composed of the true among-trees variance over years $\left(\sigma_{t}^{2}\right)$ and the variance associated with tree $\times$ year interaction $\left(\sigma_{t y}{ }^{2}\right) . \sigma_{t 1^{2}}$ accounted for only $0.3 \%$ of $\sigma_{T l^{2}}$. This very small value suggests that both among-tree variance and variance associated with the tree $x$ year interaction are small.

$\sigma_{f}^{2}$ had a large df (304) and therefore provides a reliable estimate of variance among fruits within a tree under the model.

\section{Expt. 2: Estimation of variance among} years, among trees, associated with genotype $\times$ year interaction, and tree $\times$ year interaction (two trees $\times$ eight cultivars, 12 years)

ANOVA showed that the effects of genotype, year, and genotype $\times$ year interaction were highly significant, but the tree effect was not $\left(P=0.05\right.$; Table 3). $\sigma_{g 2}{ }^{2}=400.4, \sigma_{y 2}{ }^{2}=$ $9.4, \sigma_{g y 2}{ }^{2}=7.9, \sigma_{t 2}{ }^{2}=0.2$, and $\sigma_{r 2}{ }^{2}=2.5 . \sigma_{g 2}{ }^{2}$ accounted for $95 \%$ of the total variance $\left(\sigma_{T 2}{ }^{2}\right)$, because the FRD of the cultivars ranged widely, like in Expt. 1.

$\sigma_{y 2}{ }^{2}$ accounted for only $2 \%$ of $\sigma_{T 2}{ }^{2}$. Its df was 11 , which is not large, but experiments over a dozen years are expensive and not

Table 2. Analysis of variance for fruit ripening date records of 20 fruits on two-tree replicates of eight Japanese pear cultivars/selections in a year (2005).

\begin{tabular}{lrrcc}
\hline $\begin{array}{l}\text { Source of } \\
\text { variation }\end{array}$ & \multicolumn{1}{c}{ SS } & df & MS & $\begin{array}{c}\text { Expected mean } \\
\text { squares }\end{array}$ \\
\hline Genotype & $110,587.3$ & 7 & $15,798.2^{* *}$ & $\sigma_{f 1}{ }^{2}+20 \sigma_{t t^{2}}{ }^{2}+40_{g 1}{ }^{2}$ \\
Tree (genotype) & 453.2 & 8 & $56.7 \mathrm{Ns}$ & $\sigma_{f 1}{ }^{2}+20 \sigma_{t 1}{ }^{2}$ \\
Fruit (tree genotype) & $7,779.1$ & 304 & 25.6 & $\sigma_{f 1}{ }^{2}$ \\
\hline
\end{tabular}

Ns, **Nonsignificant at $P \leq 0.05$ or significant at $P \leq 0.01$, respectively, using the $\mathrm{F}$ test.

Table 3. Analysis of variance for fruit ripening date records of two-tree replicates of eight Japanese pear cultivars/selections for 12 years.

\begin{tabular}{lrrcc}
\hline $\begin{array}{l}\text { Source of } \\
\text { variation }\end{array}$ & \multicolumn{1}{c}{ SS } & df & MS & Expected mean \\
squares
\end{tabular}

Ns, **Nonsignificant at $P \leq 0.05$ or significant at $P \leq 0.01$, respectively, using the $\mathrm{F}$ test.

easy. The year effect can be minimized by adjusting data statistically using the yearly deviation of control cultivars evaluated every year (Bell and Janick, 1990; Hansche and Brooks, 1965; Yamada et al., 1994). The small year-effect variance obtained here suggests that the efficiency of adjusting the year effect is not high.

$\sigma_{g y 2}{ }^{2}$ also accounted for only $2 \%$ of $\sigma_{T 1}^{2}$. It had a large df (77).

$\sigma_{r 2}^{2}$ is composed of the variance associated with tree $\times$ year interaction $\left(\sigma_{t y 2}{ }^{2}\right)$ and $1 / 20$ of the variance among fruits within a tree. Because $1 / 20$ of $\sigma_{f 1}{ }^{2}(25.6$, Expt. 1) was estimated at $1.3, \sigma_{t y 2}{ }^{2}$ was estimated at $1.2\left(\sigma_{r 2}^{2}-1.3\right)$.

$\sigma_{t 2}{ }^{2}$ gives an estimate of the true variance among trees within a genotype. It was very small.

The estimate of $\sigma_{t 1}{ }^{2}$ obtained in Expt. 1 is composed of the variance associated with the tree $\times$ year interaction and the variance among trees within a genotype. The latter can be estimated as $\sigma_{t 1}^{2}(1.6)-\sigma_{t y 2}^{2}(1.2)=0.4$, close to the value of $\sigma_{t 2}{ }^{2}(0.2)$ obtained here in Expt. 2.

Incorporation of the environmental variance components estimated in Expts. 1 and 2 and confidence limits of a genotypic value based on those estimates. Incorporating the results of Expts. 1 and 2 gave $\sigma_{y}{ }^{2}=9.4, \sigma_{g y}{ }^{2}=$ $7.9, \sigma_{t}{ }^{2}=0.2, \sigma_{t y}{ }^{2}=1.2$, and $\sigma_{f}^{2}=25.6$ (Table 4). This applies to the evaluation with one fruit on a single tree in a single year.

Genetic variance $\left(\sigma_{g}^{2}\right)$ was estimated by $\sigma_{g 2}{ }^{2}$ (400.4). The percentage of the genetic variance was very large $(90 \%)$, meaning that genetic differences can be easily distinguished among the eight cultivars having a wide genetic variation.

Generally, environmental variance under a given evaluation repetition was estimated as $\left\{\left(\sigma_{f}^{2} / n t y\right)+\left(\sigma_{t y}^{2} / t y\right)+\left(\sigma_{g y}^{2} / y\right)+\left(\sigma_{y}^{2} / y\right)+\right.$ $\left.\left(\sigma_{t}^{2} / t\right)\right\}$, where $n$ is the number of fruits evaluated on a tree, $t$ is the number of trees evaluated, and $y$ is the number of years.

The largest environmental variance component was the variance among fruit $\left(\sigma_{f}^{2}\right)$, which accounted for $58 \%$ of the total environmental variance. Therefore, increasing the number of
Table 4. Estimates of variance components obtained from analyses of variance estimated from Expts. 1 and 2.

\begin{tabular}{|c|c|c|c|}
\hline $\begin{array}{l}\text { Variance } \\
\text { components }\end{array}$ & Estimates & $\begin{array}{c}\text { Percent } \\
\text { estimates } \\
(\%)\end{array}$ & Calculation \\
\hline$\overline{\sigma_{g}^{2}}$ & 400.4 & 90.0 & $\sigma_{g 2}{ }^{2}$ \\
\hline$\sigma_{y}^{2}$ & 9.4 & 2.1 & $\sigma_{y 2}^{2}$ \\
\hline$\sigma_{g y}^{2}$ & 7.9 & 1.8 & $\sigma_{g y 2}^{2}$ \\
\hline$\sigma_{t}^{2}$ & 0.2 & 0.0 & $\sigma_{t 2}{ }^{2}$ \\
\hline$\sigma_{t y}^{2}$ & 1.2 & 0.3 & $\sigma_{r 2}^{2}-\left(\sigma_{f 1}^{2} / 20\right)$ \\
\hline$\sigma_{f}^{2}$ & 25.6 & 5.8 & $\sigma_{f 1}^{2}$ \\
\hline$\sigma_{T}^{2}$ & 444.7 & 100.0 & \\
\hline
\end{tabular}

fruits evaluated is the most effective way to increase the accuracy in estimating the genotypic value of a genotype or cross-seedling.

Tree replication and yearly repetitions are costly, and primary or preliminary selection in practical breeding is commonly based on the evaluation of $\approx 10$ fruits on a single tree in a year.

The FRD 95\% confidence interval of a genotypic value of a cultivar or selection using a single tree is

$$
\pm 1.96 \times \sqrt{ }\left\{\left(\sigma_{f}^{2} / n+\sigma_{t y}^{2}+\sigma_{g y}^{2}+\sigma_{y}^{2}\right) / y+\sigma_{t}^{2}\right\}
$$

where $n$ is the number of fruits evaluated on a tree and $y$ is the number of years. It is assumed that fruit on the same tree are evaluated every year and that the distribution is normal.

Yearly repetition decreases the environmental variance associated with $\sigma_{f}^{2}, \sigma_{t y}{ }^{2}$, $\sigma_{g y}{ }^{2}$, and $\sigma_{y}{ }^{2}$ but does not reduce $\sigma_{t}^{2}$. To reduce $\sigma_{t}^{2}$, tree replication is required. However, the value of $\sigma_{t}^{2}$ obtained here was negligible, and replicating trees needs a large area and high costs, so tree replication is not necessary for evaluating FRD.

The confident limits illustrated in Figure 1 show that evaluations with more than five fruits are not efficient in decreasing environmental error further. The $95 \%$ confidence limit of a genotypic value was $\pm 10 \mathrm{~d}$ in the evaluation of five fruits on a single tree in a year and $\pm 7 \mathrm{~d}$ over 2 years. Although yearly 
repetition is expensive and not easy, it is variance associated with $\sigma_{t y}{ }^{2}, \sigma_{g y}{ }^{2}$, and $\sigma_{y}{ }^{2}$.

These results are thus useful in determining optimum sample sizes and replications both in practical phenotypic selection and in QTL analysis. Those estimates seem to be useful except for the population genetically far different from the genotypes used in the present study. The secondary and ultimate selection after primary selection at NIFTS is made in a national trial, testing the performance of the selections in $\approx 30$ locations. The efficiency of the secondary selection depends on environmental variance associated with genotype $\times$ location and should be elucidated in further studies, although we estimated the variance was not large (unpublished data).

\section{Expt. 3: Estimation of genetic variance and heritability in a full-sib family from a cross}

ANOVA showed that the genetic effect of family was highly significant $(P=0.01$; Table 5). $\sigma_{g f}{ }^{2}$ and $\sigma_{p o}{ }^{2}$ were estimated at 30.3 and 82.9, respectively.

Environmental variance $\left(\sigma_{e}^{2}\right)$ is estimated as $\left\{\sigma_{g y}^{2}+\sigma_{t}^{2}+\sigma_{t y}^{2}+\left(\sigma_{f}^{2} / 5\right)\right\}=14.4$ (Table 4). Subtracting $\sigma_{e}{ }^{2}$ from $\sigma_{p o}{ }^{2}, \sigma_{g o}{ }^{2}$ was estimated at 68.5. Broad-sense heritability in a family was estimated as $\sigma_{g o}^{2} / \sigma_{p o}^{2}=0.83$. In the model, the genotypic effect in each offspring is assumed to be the genetic effect over years as shown in the Expt. 2 model. effective in decreasing the environmental

The data were obtained in a single year. When we discuss the data within the single year, the effect of genotype limited to the single year can be the sum of the true genotype effect and the genotype $\times$ year interaction in the definition of the Expt. 2 model: $(g o)_{i j}=g 2_{i j}+(g y 2)_{i j k}$ in the $j$ th offspring of the $i$ th family in the $k$ th year. In the case, $\sigma_{e}{ }^{2}$ is estimated as $\left\{\sigma_{t}^{2}+\sigma_{t y}^{2}+\left(\sigma_{f}^{2} / 5\right)\right\}=6.5$. The $\sigma_{g o}{ }^{2}$ is estimated at 76.4, and broad-sense heritability increases to 0.92 . However, selection in practical breeding is generally made in another year, and selected genotypes are grown in other years; therefore, the effect of genotype should be defined as the true genotype effect, excluding the genotype $\times$ year interaction.

The datum (value) in each offspring contains the tree effect and the tree $\times$ year interaction adding to the genotypic effect and the genotype $\times$ year interaction because each offspring has no tree replicates. Offspring population with no tree replications from a cross is common in QTL analysis. Generally, both the tree effect and the tree $\times$ year interaction are independent from the presence of the marker. If the tree effect and the tree $\times$ year interaction are large, it may not be easy to detect the marker effect in QTL analysis. Here, however, the effects of those factors are small in Japanese pear FRD.

Using environmental variance components in the same way, we can easily estimate genetic variances and heritabilities for any

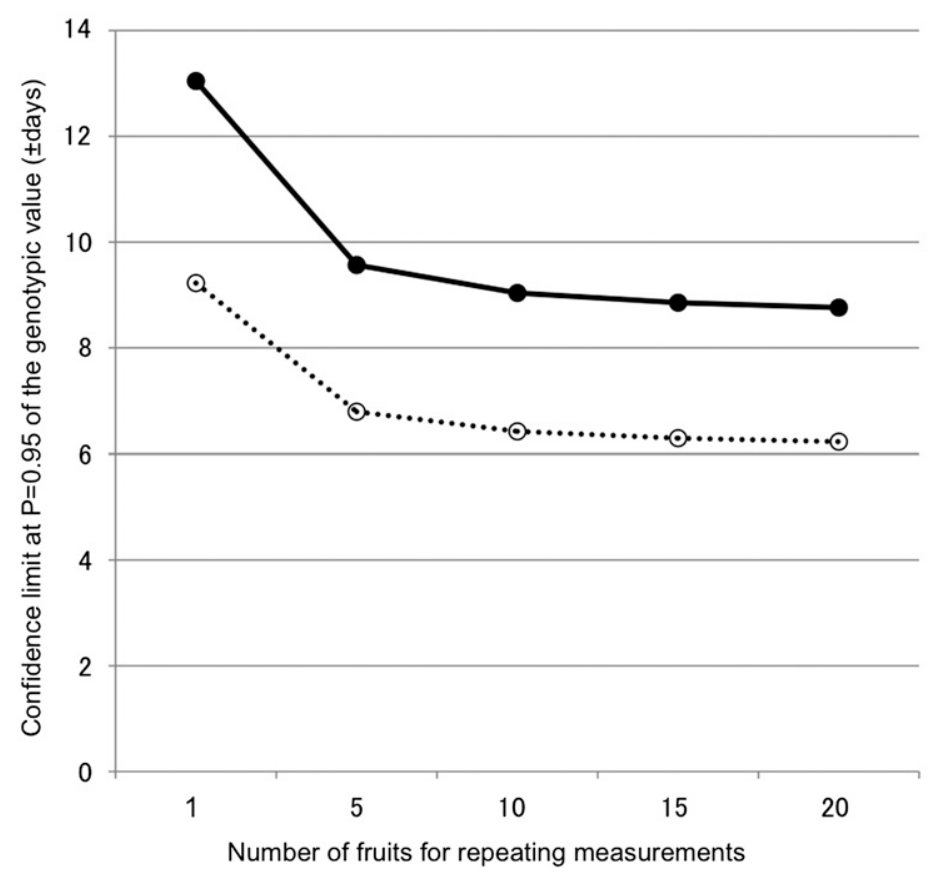

Fig. 1. Ninety-five percent confidence limits for the genotypic value of fruit ripening date with the evaluation from a single tree. Solid line $=1$-year evaluation; dotted line $=2$-year evaluation.

Table 5. Analysis of variance for fruit ripening date records of a total of 177 offspring $(60,6$, and 52 offspring each of three full-sib families) in 2009.

\begin{tabular}{lrrcl}
\hline Source of variation & SS & df & MS & Expected mean squares \\
\hline Family & $3,723.6$ & 2 & $1,861.8^{* *}$ & $\sigma_{p o}{ }^{2}+58.8 \sigma_{g f}{ }^{2}$ \\
Offspring & $144,18.7$ & 174 & 82.9 & $\sigma_{p o}{ }^{2}$ \\
\hline
\end{tabular}

**Significant at $P \leq 0.01$ using the $\mathrm{F}$ test. families subjected to QTL analysis under a given evaluation repetition in the NIFTS breeding field. Thus, the effectiveness of molecular markers associated with detected QTLs can be determined as the percentage that the markers explain in the genetic variance instead of in the phenotypic variance.

The efficiency of detecting molecular markers associated with a target trait depends on its broad-sense heritability in QTL analysis. QTL analysis for FRD can be effective in the NIFTS fields, because we obtained high heritability for a family with a small number of evaluation repetitions.

\section{Literature Cited}

Abe, K., Y. Sato, T. Saito, A. Kurihara, and K. Kotobuki. 1993. Inheritance of ripening time of fruit of Japanese pear (Pyrus pyrifolia Nakai). Jpn. J. Breed. 43:289-298.

Bell, R.L. and J. Janick. 1990. Quantitative genetic analysis of fruit quality in pear. J. Amer. Soc. Hort. Sci. 115:829-834.

Campbell, R.C. 1974. Statistics for biologists. 2nd Ed. Cambridge Univ. Press, Cambridge, $\mathrm{UK}$.

Graham, J., C.A. Hackett, K. Smith, M. Woodhead, I. Hein, and S. McCallum. 2009. Mapping QTLs for developmental traits in raspberry from bud break to ripe fruit. Theor. Appl. Genet. 118: 1143-1155.

Hansche, P.E. 1983. Response to selection, p. 154171. In: Moore, J.N. and J. Janick (eds.). Methods in fruit breeding. Purdue Univ. Press, West Lafayette, IN.

Hansche, P.E. and V. Beres. 1966. An analysis of environmental variability in sweet cherry (Prunus avium L.). Proc. Amer. Soc. Hort. Sci. 88:173183.

Hansche, P.E. and R.M. Brooks. 1965. Temporal and spatial repeatability of a series of quantitative characters in sweet cherry (Prunus avium L.). Proc. Amer. Soc. Hort. Sci. 86:120-128.

Iketani, H., K. Abe, T. Yamamoto, K. Kotobuki, Y. Sato, T. Saito, O. Terai, N. Matsuta, and T. Hayashi. 2001. Mapping of disease-related genes in Japanese pear using a molecular linkage map with RAPD markers. Breed. Sci. 51:179-184.

Kajiura, M., and Y. Sato. 1990. Recent progress in Japanese pear (Pyrus pyrifolia Nakai) breeding and descriptions of cultivars based on literature review. Bull. Fruit Tree Res. Sta. Extra No. 1. P. 1-329 [in Japanese with English abstract].

Kajiura, M., K. Suzuki, and T. Yamazaki. 1975. Color chart for Japanese pear (Pyrus serotina var. culta Rehder). HortScience 10:257-258.

Kanayama, Y. 2006. Horticultural statistics of Japan, p. 15-20. In: Jpn. Soc. Hort. Sci. (ed.). Horticulture in Japan 2006. Shoukadoh, Kyoto, Japan.

Kenis, K., J. Keulemans, and M.W. Davey. 2008. Identification and stability of QTLs for fruit quality traits in apple. Tree Genet. Genomes 4:647-661.

Moriya, S., H. Iwanami, S. Takahashi, N. Kotoda, K. Suzaki, T. Yamamoto, and K. Abe. 2010. Genetic mapping of the crown gall resistance gene of the wild apple Malus sieboldii. Tree Genet. Genomes 6:195-203.

Nishitani, C., S. Terakami, Y. Sawamura, N. Takada, and T. Yamamoto. 2009. Development of novel EST-SSR markers derived from Japanese pear (Pyrus pyrifolia). Breed. Sci. 59:391-400.

Nyquist, W.E. 1991. Estimation of heritability and prediction of selection response in plant populations. Crit. Rev. Plant Sci. 10:235-322. 
Okada, K., N. Tonaka, Y. Moriya, N. Norioka, Y. Sawamura, T. Matsumoto, T. Nakanishi, and T. Takasaki-Yasuda. 2008. Deletion of a $236 \mathrm{~kb}$ region around $S_{4}$-RNase in a stylar-part mutant

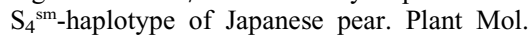
Biol. 66:389-400.

Quilot, B., B.H. Wu, J. Kervella, M. Genard, M. Foulongne, and K. Moreau. 2004. QTL analysis of quality traits in an advanced backcross between Prunus persica cultivars and the wild relative species $P$. davidiana. Theor. Appl. Genet. 109: 884-897.

Sato, A., M. Yamada, H. Iwanami, and N. Hirakawa. 2000. Optimal spatial and temporal measurement repetition for reducing environmental variation of berry traits in grape breeding. Sci. Hort. 85:75-83.

Segura, V., C.-E. Durel, and E. Costes. 2009. Dissecting apple tree architecture into genetic, ontogenetic and environmental effects: QTL mapping. Tree Genet. Genomes 5:165-179.

Tamura, F. 2006. Japanese pear, p. 50-58. In: Jpn. Soc. Hort. Sci. (ed.). Horticulture in Japan 2006. Shoukadoh Publication, Kyoto, Japan.
Terakami, S., Y. Adachi, H. Iketani, Y. Sato, Y. Sawamura, N. Takada, C. Nishitani, and T. Yamamoto. 2007. Genetic mapping of genes for susceptibility to black spot disease in Japanese pears. Genome 50:735-741.

Terakami, S., T. Kimura, C. Nishitani, Y. Sawamura, T. Saito, T. Hirabayashi, and T. Yamamoto. 2009. Genetic linkage map of the Japanese pear 'Housui' identifying three homozygous genomic regions. J. Jpn. Soc. Hort. Sci. 78: 417-424.

Terakami, S., M. Shoda, Y. Adachi, T. Gonai, M. Kasumi, Y. Sawamura, H. Iketani, K. Kotobuki, A. Patocchi, C. Gessler, T. Hayashi, and T. Yamamoto. 2006. Genetic mapping of the pear scab resistance gene Vnk of Japanese pear cultivar Kinchaku. Theor. Appl. Genet. 113: $743-752$.

Ukai, Y. 2000. Genetic analysis at the genomic level: Map and QTL. University of Tokyo Press, Tokyo, Japan [in Japanese].

Yamada, M., A. Sato, and Y. Ukai. 2002. Genetic differences and environmental variations in calyx-end fruit cracking among Japanese persimmon cultivars and selections. HortScience 37:164-167.

Yamada, M., H. Yamane, and Y. Ukai. 1994. Efficiency of use of control genotypes for reducing yearly fluctuations of quantitative fruit characters in Japanese persimmon breeding. Bull. Fruit Tree Res. Sta. 26:2937.

Yamada, M., H. Yamane, K. Yoshinaga, and Y. Ukai. 1993. Optimal temporal and spatial measurement repetition for selection in Japanese breeding. HortScience 28:838-841.

Yamamoto, T., T. Kimura, S. Terakami, C. Nishitani, Y. Sawamura, T. Saito, K. Kotobuki, and T. Hayashi. 2007. Integrated reference genetic linkage maps of pear based on SSR and AFLP markers. Breed. Sci. 57:321-329.

Zhang, G., A.M. Sebolt, S.S. Sooriyapathirana, D. Wang, M.C. Bink, J.W. Olmstead, and A.F. Iezzoni. 2010. Fruit size QTL analysis of an F1 population derived from a cross between a domesticated sweet cherry cultivar and a wild forest sweet cherry. Tree Genet. Genomes 6: $25-36$. 